\title{
VENTURE CAPITAL AND CORPORATE INNOVATION INPUT FROM THE PERSPECTIVE OF SYNDICATED INVESTMENT
}

\author{
Ning Jiang ${ }^{1}$, Yuan Yang ${ }^{1 *}$, Bingkun Yang ${ }^{1}$, Wenli Huang ${ }^{2}$ \\ ${ }^{1}$ China Academy of Financial Research, Zhejiang University of Finance and Economics, \\ Hangzhou, China. \\ ${ }^{2}$ China Academy of Financial Research, Zhejiang University of Finance and Economics, \\ Hangzhou, China. Email: wlhuangmath@126.com \\ * Corresponding Author. Email: yangyuan024@163.com
}

\begin{abstract}
Using data for 341 enterprises listed on the Growth Enterprise Market (GEM) of the Shenzhen Stock Exchange and taking R\&D expenditure as an indicator of innovation investment, this paper implements multiple linear regression to test whether venture capital promotes corporate innovation input. It also considers the relationship between the syndicated investment of venture capital and innovation input. The results show that venture capital indeed promotes $R \& D$ in the invested enterprises. The innovation input of syndicated investment enterprises is significantly higher than that of sole investment enterprises. Under syndicated investment, the higher the number of syndicated investment members and the greater the heterogeneity of the shareholding ratio among the members, the higher is the innovation input. The reputation of the syndicated investment team, however, has no significant impact on innovation input.
\end{abstract}

Keywords: Venture capital; Syndicated investment; Innovation input.

JEL Classification: G24.

Article history:

Received : January 4, 2019

Revised : March 23, 2019

Accepted : April 6, 2019

Available online : April 30, 2019

https://doi.org/10.21098/bemp.v22i1.1036 


\section{INTRODUCTION}

Enterprises are the main players in market economies. Their technological innovation capabilities are closely related to their performance and growth. More specifically, factors such as enterprise financing methods, governance structure, and level of financial market development and related policies will have differing impacts on enterprise innovation activity. Capital is a decisive input factor, since financing constraints inhibit innovation activities of enterprises. Generally, the innovation input of enterprises stems from internal and external financing. The former refers mainly to enterprises using their own capital investment, while the latter mainly pertains to banking system (in debt financing markets) and Venture Capital (VC) (in equity financing markets) (Fei, 2010). In choosing target borrowers, banks focus mainly on company size, collateral and income level, but VC is not sensitive to these factors. Therefore, in Small and Medium Enterprises (SME) financing, VC has several advantages over bank financing (Liang, 2015).

VC can not only provide sufficient funding for enterprises, it also may actively participate in the management of invested companies. VC provides a range of value-added services, such as helping to improve corporate governance structure, providing consultation and support in human resources, among others. VC has characteristics that differ from traditional financial and industrial capital, and its new financing method of "financing + cooperating" is highly valued by the Chinese government. Some local governments in China have already introduced a series of policies to encourage VC development through tax incentives, other one-off incentives or subsidies, and loss compensation. For example, if investing eligibly in unlisted small and medium-sized high-tech enterprises through equity investment for more than 2 years, a VC enterprise may deduct $70 \%$ of the investment amount from taxable income in the year following the 2-year investment period; when taxable income for the year is less than the deduction, it may be deducted in the subsequent tax year. ${ }^{3}$ Further, VC and Angel investors are allowed to withdraw risk reserves, which are used to compensate investment losses, based on $10 \%$ of the fund's long-term investment balance. ${ }^{4}$ In the current environment, it is especially important to understand whether VC firms meet policy expectations and play an important role in promoting corporate innovation.

VC firms face high investment risk, so they often adopt a syndicated investment strategy; that is, several VC firms jointly invest in a target enterprise. Syndicated investment is vital in the VC market. Compared with individual investment, it can not only diversify risk, but also integrate the advantages of each investor to generate a resource-sharing effect and a value-sharing effect. Therefore, this syndicated investment strategy is highly favored by both VC firms and invested companies.

There is little literature on the relationship between VC and enterprise innovation in China, and research on how the characteristics of VC firms influence enterprise innovation are even rarer. The relationship between VC and enterprise

\footnotetext{
3 See "Implementation Opinions of the People's Government of Jiangxi Province on Promoting a Number of Policy Measures for Mass Entrepreneurship and Innovation."

4 See "Implementation Opinions of the People's Government of Zhejiang Province on Promoting Mass Entrepreneurship and Innovation."
} 
innovation requires additional empirical evidence. To enrich the existing research on VC and enterprise innovation in China, this paper takes the companies listed on the GEM market of the Shenzhen Stock Exchange as a sample to explore the impact of $\mathrm{VC}$ on corporate innovation input and the role of the syndicated investment strategy of VC firms. It also examines the impact of the characteristics of VC on innovation input under syndicated investment.

This work is significant for several reasons. It is based on VC, a vital component of the equity financing market, ${ }^{5}$ and it verifies and supplements prior research on VC and enterprise innovation. Existing research on the relationship between VC investment form and strategy and corporate innovation investment is not sufficient. Therefore, this paper uses a VC syndicated investment sample to supplement the literature. Further, this paper explores the varying impacts of various characteristics of syndicated investment teams on enterprise innovation input, to determine what form of syndicated investment can better enhance the incubation of innovation. The purpose of this paper is to help improve the efficiency of incubation of innovation by providing a reference framework for VC firms to choose syndicated investment partners. In addition, it will help innovative enterprises choose suitable VC firms.

\section{LITERATURE REVIEW AND HYPOTHESIS}

A. $V C$ and Enterprise Innovation

It is generally believed that VC is a major factor behind the high level of technological innovation in American companies (Keuschnigg, 2004). According to Kortum and Lerner (2000), VC-backed companies are more innovative and have more valuable patents. Hellmann and Puri $(2000,2002)$ show that, compared with non-VC-backed companies, VC-backed companies are more radical in innovation, the speed at which products are introduced into the market is significantly faster, and their market strategies are more radical. Tian and Wang (2011) find, from the perspective of failure tolerance, that Initial Public Offerings (IPO) companies supported by VC with high risk tolerance are more innovative, and the impact of failure tolerance on company innovation is on a sustained basis. That is, the attitude of VC firms toward failure may be internalized by the company and become part of the corporate culture, which can help the company to form a unique culture of innovation. However, some research does not fully recognize the role of VC in promoting corporate innovation. Roosenboom and Popov (2012) use data from several countries and find that the positive impact of VC exists only in countries where the VC industry thrives. Further, in countries where VC is supported by the government, businesses are easy to start, taxation is low, and the regulatory environment is loose, making it more conducive for $\mathrm{VC}$ firms to promote enterprise innovation.

Zheng and Li (2001) believe that VC plays an irreplaceable role in helping small- and medium-sized startups. VC can supervise a company's innovation activities and use its own rich market experience to guide and correct the direction

5 According to Zhang and Liao (2011) and Chen et al. (2017), this paper does not distinguish between $\mathrm{VC}$ and PE, and collectively refers to both as VC. 
of enterprise innovation. At the same time, participation of VC reduces the degree of information asymmetry between investors and enterprises. Wu (2009) believes that the integration of capital and technology brought about by VC capital support and its participation in enterprise management promotes enterprise innovation. Fu et al. (2012) find that compared with other institutional investors, VC can better promote innovation investment in GEM companies. Chen et al. (2017) and Wang and $\mathrm{Hu}$ (2017) also find that VC plays a significant role in improving innovation performance.

VC firms are professional investors that usually specialize in particular investment fields. They accumulate ind ustry resources and gain relevant experience in business management (Chen et al., 2017). VC often participates actively in the operation and governance of the invested company by joining the board. They use professional management experience to improve corporate governance structure and provide support in areas such as strategy making, human resources, and financing. These value-added services are especially useful in the invested firms' innovation activities, since they overcome defects in terms of business management and resources. At the same time, VC can effectively supervise innovation activities of the invested companies, ensuring their quality and efficiency. Compared with traditional corporate activities (such as manufacturing and marketing), innovation activities are always accompanied by high risk stemming from the large amount of investment, the long-term research and development process, and many other unpredictable factors (Holmstrom, 1989). Fortunately, the high risk in corporate innovation activity may bring high returns-investors have a chance to gain higher exit returns. Accordingly, we propose the following hypothesis:

Hypothesis 1: VC participation has a positive impact on corporate innovation.

\section{B. Syndicated Investment and Corporate Innovation Input}

As a common investment strategy for VC, syndicated investment has more advantages than individual investment. For example, syndicated investment enables resource sharing and provides invested enterprises with rich resources and value-added services. Moreover, syndicated investment behavior reduces information asymmetry, conveys a positive signal that the company is worth investing, thus attracting more investors to fund the company's innovation activities (Leland and Pyle, 1977). The literature also finds that syndicated investment-backed companies have better competence in corporate governance, and there is a positive correlation between this competence and the number of syndicated investment members (Shen and $\mathrm{Hu}, 2014$ ). In addition, Tian (2012) analyzes 30,861 companies and concludes that syndicated investment can not only promote incubation of innovative products and improve their market value, it also improves IPO performance. We thus propose Hypothesis 2:

Hypothesis 2: Compared with sole investment enterprises, innovation input in syndicated investment enterprises is higher. 


\section{Characteristics of Syndicated Investment and Enterprise Innovation Input}

The syndicated investment model is favored by VC firms in several countries. But how will syndicated investment with different characteristics affect enterprise innovation input? The present paper discusses the relationship between enterprise innovation input and syndicated investment characteristics, such as number of investment members, reputation characteristics, and proportion of shareholding.

First, more risk organizations involved in syndicated investment means more financial support, professional guidance, and other resources. Further, they also bring a higher level of risk diversification. Lu et al. (2017) show that the innovation ability of the invested company grows with the number of syndicated investment institutions. Therefore, we propose Hypothesis 3:

Hypothesis 3: The innovation input of the invested company is positively correlated with the number of institutions that invest in a syndicated investment.

Reputable VC firms often have rich investment experience and a wellestablished network of relationships. They play a positive role in discovering and nurturing high-quality enterprises, providing better value-added services and support for the invested enterprises. Therefore, VC firms with strong reputation are more attractive, and the enterprises backed by them are undoubtedly favored by the market. Gompers et al. (1996) suggest that a "reputation chasing motivation" exists in younger institutions - they try to build their reputation and raise new funds as soon as possible by listing their invested companies earlier than do mature institutions. Although this "reputation chasing behavior" can increase the short-term value of invested companies (for example, reducing R\&D expenses in the short-term can increase profit in the current period), it sacrifices long-term value. Based on the analysis above, we propose Hypothesis 4:

Hypothesis 4: Firm innovation input is positively correlated with the reputation of the syndicated investment team.

Finally, differences in shareholding ratio among members of the syndicated investment will influence investment results. Generally, syndicated investment can diversify investment risk. If there are large differences in members' investment amounts, however, the effect of risk diversification will be nullified. When a particular member holds a relatively large proportion of shares, moral hazard tends to occur and other members are prone to "free-riding," which reduces the positive impact of syndicated investment on corporate innovation. Therefore, more dispersed shareholding can diversify investment risk and enable each syndicated investment member to participate in corporate governance and promote corporate innovation more actively. Based on the analysis above, we propose our fifth hypothesis:

Hypothesis 5: The heterogeneity of syndicated investment members' shareholding ratio is an unfavorable factor in enterprise innovation input.

\section{RESEARCH DESIGN}

\section{A. Sample and Data}

We select firms listed on the GEM market of the Shenzhen Stock Exchange over the period January 1, 2012 to July 14, 2017 as our initial sample; we use annual data. On the one hand, the GEM was originally created to provide an ideal exit 
channel for domestic VC, and it brings together many VC-backed companies. On the other hand, unlike the main board or SME board, the GEM is more suitable for listing VC-supported enterprises. Therefore, the Shenzhen GEM, founded in 2009, provides a good research sample for our study.

Our data comprise three parts: (1) VC data: a sample of VC-backed firms listed on the Shenzhen GEM from 2012 to 2017 (obtained from CVsource ${ }^{6}$ ) and relevant data on VC firms, such as year of establishment (obtained from Wind ${ }^{7}$ ). For data that cannot be obtained from these databases, we collect data manually through publicly available resources, such as prospectuses of the listed companies. (2) Indicator of company's innovation capability (R\&D data), from iFinD ${ }^{8}$. (3) Relevant financial information for listed companies, from CSMAR 9

After excluding companies with missing data and financial enterprises, the final sample includes 341 companies, of which $227(66.57 \%)$ have a VC background at the time of listing. Judging from yearly data, VC-backed enterprises form the majority, accounting for more than $60 \%$ every year.

\section{B. Variable Definitions}

\section{B1. Dependent Variable}

Our dependent variable is listed company $R \& D$ expenditure. As an indicator that every listed company must reveal, $R \& D$ expenditure is highly available and representative. It measures company investment in innovation activities and can reflect company attitude toward them, showing the most timely and direct performance of company efforts in innovation. Therefore, based on existing research, this paper takes the natural logarithm of R\&D expenditure to measure company innovation input (Zhan et al., 2015).

\section{B2. Independent Variables}

We set two dummy variables, VC (VC) and syndicated investment (Syn). Drawing on $\mathrm{Wu}$ et al. (2012), we judge whether the shareholders of the company are VC firms by consulting databases, the investment community, the website "sky-eye inspection ${ }^{10 \prime}$, and prospectuses. If at least one investing institution among the topten shareholders at the time of listing is a VC firm, the company is regarded as a VC-backed company, $V C=1$, otherwise $V C=0$. If there is more than one VC firms among the top-ten shareholders, it is a syndicated investment, $S y n=1$, otherwise it is considered an independent investment, $S y n=0$.

SynNum refers to the number of VC firms among the top-ten shareholders in the syndicated investment sample. Further, the reputation of the syndicated investment team (SynRep) is measured using the reputation of the leading VC firms, while the institution's reputation is measured by its age, that is, the number of years between establishment of the institution and the IPO of its invested

\footnotetext{
6 See https://www.cvsource.com.cn/

7 See https://www.wind.com.cn/

8 See http://www.51ifind.com/

9 See http://us.gtadata.com/

${ }_{10}$ See https://www.tianyancha.com/
} 
company. When the age of the leading institution is equal to or greater than 6 years, SynRep=1, otherwise SynRep $=0$.

Both Gomper (1996) and Hsu (2004) believe that an institution's age is, to some extent, a suitable indicator of a 's experience and reputation. Gomper (1996) separates high-reputation VCs from low-reputation VCs in terms of whether age is greater than 6 years. This author finds that there are 12 significant differences between these two kinds of $\mathrm{VC}$, such as the average amount of subsequent fundraising, the leading VC's number of seats in the invested company's board and its shareholding ratio in the company. Due to data availability, we also use VC age to measure reputation, taking 6 years as the dividing line.

In portraying the heterogeneity of VC shareholding ratio, this paper draws on Beckman and Haunschild (2002) and Lu et al. (2017) to construct a coefficient of variation for measuring the heterogeneity of the continuous variables, that is, the ratio of standard deviation to mean of the shareholding ratio. The larger the ratio, the greater the heterogeneity of the shareholding ratio between different syndicated investment members. The heterogeneity indicator is built as follows:

$$
\text { ShareHetero }=\frac{\sqrt{\mathrm{E}\left(\text { Share }_{i}-\mathrm{E}\left(\text { Share }_{i}\right)\right)^{2}}}{\mathrm{E}\left(\text { Share }_{i}\right)}=\frac{\sigma_{\text {Share }_{i}}}{\mathrm{E}\left(\text { Share }_{i}\right)},
$$

where Share $_{i}$ is the shareholding ratio of VC firms $i$.

\section{B3. Control Variables}

Based on the literature, this paper takes company size, profitability, solvency, and policy factors as control variables (Chemmanur et al., 2004; Chen et al., 2017; Lu et al., 2017). Company size (Lnasset) is the natural logarithm of the company's total assets at the end of a year; profitability $(R O E)$ is the ratio of company net profit to total equity at the end of a year; solvency ( $L e v)$ is the ratio of company total liabilities to total assets at the end of a year; policy factor (Lngov) is the natural logarithm of government subsidies received by the company.

Table 1.

Variable Definition

In this table, all variables appearing in this paper are defined and explained.

\begin{tabular}{|c|c|c|c|}
\hline & Variable & Definition & Variable Name \\
\hline $\begin{array}{l}\text { Dependent } \\
\text { Variable }\end{array}$ & Innovation Input & $\begin{array}{l}\text { the natural logarithm of } \\
\text { company R\&D expenditure }\end{array}$ & $\operatorname{LnR\mathcal {E}D}$ \\
\hline \multirow{3}{*}{$\begin{array}{l}\text { Independent } \\
\text { Variables }\end{array}$} & Venture Capital & $\begin{array}{l}\text { dummy variable, } V C=1 \text { if it is a } \mathrm{VC} \text { - } \\
\text { backed company, otherwise } V C=0\end{array}$ & $V C$ \\
\hline & $\begin{array}{l}\text { Syndicated } \\
\text { Investment }\end{array}$ & $\begin{array}{c}\text { dummy variable, } S y n=1 \text { if it is a } \\
\text { syndicated investment, otherwise } \\
S y n=0\end{array}$ & Syn \\
\hline & $\begin{array}{l}\text { Number of VC } \\
\text { firms }\end{array}$ & $\begin{array}{l}\text { number of VC firms among the top- } \\
\text { ten shareholders in the syndicated } \\
\text { investment sample }\end{array}$ & SynNum \\
\hline
\end{tabular}


Table 1.

Variable Definition (contd.)

In this table, all variables appearing in this paper are defined and explained.

\begin{tabular}{|c|c|c|c|}
\hline & Variable & Definition & Variable Name \\
\hline \multirow[t]{2}{*}{$\begin{array}{l}\text { Independent } \\
\text { Variables }\end{array}$} & $\begin{array}{l}\text { Syndicated } \\
\text { Investment Team } \\
\text { Reputation }\end{array}$ & $\begin{array}{l}\text { leading VC firm's age, dummy } \\
\text { variable, SynRep }=1 \text { if the age of } \\
\text { the leading institution is equal to } \\
\text { or greater than } 6 \text { years, otherwise } \\
\text { SynRep }=0 .\end{array}$ & SynRep \\
\hline & $\begin{array}{l}\text { Heterogeneity of } \\
\text { VC Shareholding } \\
\text { Ratio }\end{array}$ & $\begin{array}{l}\text { VC Shareholding Ratio } \\
\text { Heterogeneity in the year of the } \\
\text { invested company's IPO }\end{array}$ & ShareHetero \\
\hline \multirow{4}{*}{ Control Variables } & Company Size & $\begin{array}{c}\text { the natural logarithm of the } \\
\text { company's total assets at the end } \\
\text { of a year }\end{array}$ & Lnasset \\
\hline & Profitability & $\begin{array}{l}\text { the ratio of company net profit to } \\
\text { total equity at the end of a year }\end{array}$ & $R O E$ \\
\hline & Solvency & $\begin{array}{l}\text { the ratio of company total liabilities } \\
\text { to total assets at the end of a year }\end{array}$ & Lev \\
\hline & Policy Factor & $\begin{array}{l}\text { the natural logarithm of } \\
\text { government subsidies received by } \\
\text { the company }\end{array}$ & Lngov \\
\hline Other Variables & VC Participation & $\begin{array}{l}\text { dummy variable, Inv_after }=1 \\
\text { if it is an observation after VC } \\
\text { participation, Inv_after }=0 \text { if it is an } \\
\text { observation before VC participation }\end{array}$ & Inv_after \\
\hline
\end{tabular}

C. Model Design

To analyze the impact of VC participation on the innovation input of the invested company, this paper draws on Chen et al. (2017) and builds a model to examine the difference between enterprises with and without VC participation. At the same time, it also illustrates how the innovation input of VC-backed companies changes after VC firms join in.

$$
\operatorname{LnR\mathcal {E}D_{it}}=\alpha_{0}+\alpha_{1} \text { VC }^{*} I n v_{-} \text {after }_{i t}+\alpha_{j} \text { Control }_{i t}+Y_{i}+\lambda_{t}+\varepsilon_{i t}
$$

Inv_after is a dummy variable that measures whether a VC firm joins in: Inv_after=1 indicates an observation after VC participation, and Inv_after $=0$ indicates an observation before VC participation. VC Inv_after is the cross term between VC and Inv_after: value 1 means observation of VC-backed companies after VC participation, and value 0 means absence of VC participation or an observation one year before VC participation. Control indicates other control variables, while $Y$ and $\lambda$ indicate the controls for year and industry fixed effects, respectively. 
To verify Hypotheses $2-5$, the following model is established:

$$
\operatorname{LnRED} D_{i}=\alpha_{0}+\alpha_{1} X_{i}+\alpha_{2} \text { Lnasset }_{i}+\alpha_{3} \text { Roe }_{i}+\alpha_{4} \text { Lngov }_{i}+\alpha_{5} \text { Lev }_{i}+\varepsilon_{i}
$$

where $X$ refers to syndicated investment characteristics: whether the investment is syndicated $(S y n)$, number of syndicated investment members (SynNum), reputation (SynRep), and shareholding ratio (ShareHetero).

D. Descriptive Statistics

Table 2.

Summary Statistics on Main Variables

Use the following to interpret this table. (A) Coefficients significant at the $10 \%, 5 \%$ and $1 \%$ level are indicated with $*$, *****, respectively; the content in () is the $t$-statistic. (B) For variable definitions, please check Table 1. (C) Only 208 VC-backed companies received syndicated investment, so Syn has 208 observations, of which 145 companies have complete data in the number of syndicated investment members (SynNum), reputation (SynRep), and the heterogeneity of shareholding ratio (ShareHetero).

\begin{tabular}{|c|c|c|c|c|c|}
\hline \multicolumn{6}{|c|}{ Panel A: the whole sample } \\
\hline Variables & $\begin{array}{c}\text { Number of } \\
\text { Observations }\end{array}$ & Mean & Std. Dev. & Min. & Max. \\
\hline $\operatorname{LnRED}$ & 1336 & 16.713 & 0.772 & 11.816 & 20.858 \\
\hline VC*Inv_after & 1336 & 0.495 & 0.500 & 0 & 1 \\
\hline Syn & 208 & 0.697 & 0.461 & 0 & 1 \\
\hline SynNum & 145 & 3.124 & 1.269 & 2 & 7 \\
\hline SynRep & 145 & 0.710 & 0.455 & 0 & 1 \\
\hline ShareHetero & 145 & 1.694 & 0.733 & 0 & 2.999 \\
\hline Lnasset & 1336 & 19.975 & 0.713 & 17.730 & 23.743 \\
\hline$R O E$ & 1336 & 24.820 & 13.146 & 1.475 & 148.838 \\
\hline Lngov & 1336 & 15.225 & 1.355 & 0 & 19.764 \\
\hline Lev & 1336 & 33.992 & 16.655 & 1.103 & 91.070 \\
\hline \multicolumn{6}{|c|}{ Panel B: companies with and without VC participation } \\
\hline \multirow[t]{2}{*}{ Variables } & \multicolumn{2}{|c|}{$\begin{array}{c}\text { Companies without VC } \\
\text { Participation } \\
(\mathrm{N}=447)\end{array}$} & \multicolumn{2}{|c|}{$\begin{array}{l}\text { Companies with VC } \\
\text { Participation } \\
(\mathrm{N}=889)\end{array}$} & \multirow[t]{2}{*}{$\begin{array}{c}\text { Whether } \\
\text { Supported } \\
\text { by VC }\end{array}$} \\
\hline & Mean & Std. Dev. & Mean & Std. Dev. & \\
\hline $\operatorname{LnRED}$ & 16.654 & 0.786 & 16.742 & 0.763 & $\begin{array}{l}-0.088^{* *} \\
(-1.973)\end{array}$ \\
\hline Lnasset & 19.961 & 0.770 & 19.983 & 0.683 & $\begin{array}{c}-0.022 \\
(-0.537)\end{array}$ \\
\hline$R O E$ & 27.361 & 14.861 & 23.542 & 12.000 & $\begin{array}{c}3.819^{* * *} \\
(5.057)\end{array}$ \\
\hline Lngov & 15.075 & 1.463 & 15.301 & 1.292 & $\begin{array}{l}-0.226^{* * *} \\
(-2.890)\end{array}$ \\
\hline Lev & 33.610 & 17.709 & 34.184 & 16.106 & $\begin{array}{c}-0.574 \\
(-0.594)\end{array}$ \\
\hline
\end{tabular}


Table 2 shows summary statistics on the main variables. Panel A refers to the entire sample. Note that the proportion of observations of VC-backed companies after VC participation is $49.5 \%$, almost half the whole sample; the average value of

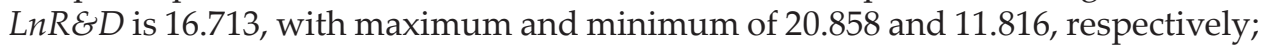
and $69.7 \%$ of 208 VC-backed enterprises obtained syndicated investment. As for syndicated investment characteristics, the average number of syndicated investment members is 3.124, that is, each company has an average of $3 \mathrm{VC}$ firms investing jointly; average age of the leading VC is 0.71 , which indicates that $71 \%$ of the leading VCs have an age of more than 6 years; average value of shareholding ratio heterogeneity is 1.694 , with the smallest among them 0 , which means that every VC has the same shareholding ratio. Panel B shows T-test results of companies with and without VC participation: R\&D expenditure of VC-backed enterprises is significantly higher than that of non-VC-backed enterprises; meanwhile, there are significant differences in Return on Equity $(R O E)$ and government subsidies between these two kinds of companies.

\section{EMPIRICAL RESULTS AND ANALYSIS}

\section{A. VC and Innovation Input}

This part shows the main empirical results of this paper and analyzes the relationship between innovation input and VC/syndicated investment characters.

\section{A1. Endogeneity of VC and Innovation Input}

When investing in a venture, VC firms consider factors such as market attractiveness, strategy, technology, products or services, customer usage, competition, trading conditions, and the quality and experience of the management team (Kaplan and Stromberg, 2004). The target company may have its own advantages in innovation, in which case our research will face endogeneity. Therefore, to rule out the possibility that the two kinds of companies have different levels of innovation input before VCs make their investment, this paper performs a regression with the data of companies without VC participation and VC-backed company observation one year before VC participation. Table 3 shows the regression results: in all five columns, the regression coefficients of $\mathrm{VC}$ are positive, but they are small and not significant, which means that R\&D expenditure of VC-backed enterprises before VC participation is not significantly higher than that of non-VC-backed enterprises in the same time period. Further, we use a Probit regression to examine the relationship between VC investing decision factors and enterprise innovation input. If the coefficient of $R \& D$ is significant, the $R \& D$ expenditure level of the enterprise can be regarded as an important factor to attract VC; that is, VC firms pay special attention to the R\&D expenditure of the target enterprise when selecting their investment projects. Thus, this indicates that the difference between the R\&D expenditures of VC-backed enterprises and non-VC-backed enterprises already exists prior to VC participation. Table 4 shows that the coefficient of R\&D expenditure is not significant, which means that, in our sample, R\&D expenditure may not influence VC investing decisions. 
Table 3.

R\&D Before the VC Participation

Use the following to interpret this table. (A) Coefficients significant at the $10 \%, 5 \%$ and $1 \%$ level are indicated with *,**, ***, respectively; the content in () is the $t$-statistic. (B) For variable definitions, please check Table 1. (C) Column (1) shows the regression results without control variables, columns (2)-(5) show the results that contain one more control variable than the previous column.

\begin{tabular}{lccccc}
\hline \multirow{2}{*}{ Variables } & \multicolumn{5}{c}{ LnR\&D } \\
\cline { 2 - 6 } & $\mathbf{( 1 )}$ & $\mathbf{( 2 )}$ & $\mathbf{( 3 )}$ & $\mathbf{( 4 )}$ & $\mathbf{( 5 )}$ \\
\hline VC & 0.055 & 0.017 & 0.084 & 0.064 & 0.066 \\
Lnasset & $(0.67)$ & $(0.30)$ & $(1.52)$ & $(1.22)$ & $(1.30)$ \\
& & $0.745^{* * *}$ & $0.805^{* * *}$ & $0.748^{* * *}$ & $0.827^{* * *}$ \\
ROE & $(15.48)$ & $(19.09)$ & $(17.55)$ & $(18.48)$ \\
& & & $0.011^{* * *}$ & $0.010^{* * *}$ & $0.010^{* * *}$ \\
Lngov & & $(5.99)$ & $(6.09)$ & $(6.48)$ \\
& & & $0.100^{* * *}$ & $0.089^{* * *}$ \\
Lev & & & $(4.58)$ & $(4.23)$ \\
& & & & & $-0.007^{* * *}$ \\
Constant & $15.078^{* * *}$ & -0.597 & $-2.159^{* *}$ & $-2.581^{* * *}$ & $-3.541^{* * *}$ \\
& $(182.33)$ & $(-0.59)$ & $(-2.39)$ & $(-2.99)$ & $(-4.14)$ \\
\hline Obs & 341 & 341 & 341 & 341 & 341 \\
$R^{2}$ & 0.1690 & 0.5591 & 0.5970 & 0.6224 & 0.6427 \\
\hline
\end{tabular}

Table 4.

The Relationship between VC's Investing Decision Factors and the Invested Company's R\&D Expenditure

Use the following to interpret this table. (A) Coefficients significant at the $10 \%, 5 \%$ and $1 \%$ level are indicated with *******, respectively; the content in () is the t-statistic. (B) For variable definitions, please check Table 1. (C) Column (1) shows the regression results without control variables, columns (2)-(5) show the results that contain one more control variable than the previous column.

\begin{tabular}{lccccc}
\hline \multirow{2}{*}{ Variables } & \multicolumn{5}{c}{ VC } \\
\cline { 2 - 6 } & $\mathbf{( 1 )}$ & $\mathbf{( 2 )}$ & $\mathbf{( 3 )}$ & $\mathbf{( 4 )}$ & $\mathbf{( 5 )}$ \\
\hline LnRED & 0.072 & 0.039 & 0.224 & 0.185 & 0.202 \\
& $(0.70)$ & $(0.27)$ & $(1.46)$ & $(1.16)$ & $(1.24)$ \\
Lnasset & & 0.049 & -0.212 & -0.214 & -0.253 \\
& & $(0.32)$ & $(-1.24)$ & $(-1.26)$ & $(-1.32)$ \\
ROE & & $-0.022^{* * *}$ & $-0.022^{* * *}$ & $-0.023^{* * *}$ \\
& & & $(-3.86)$ & $(-3.83)$ & $(-3.83)$ \\
Lngov & & & 0.061 & 0.062 \\
& & & & $(0.96)$ & $(0.99)$ \\
Lev & & & & 0.002 \\
& & & & & $(0.44)$ \\
Constant & -0.753 & -1.187 & 1.463 & 1.200 & 1.551 \\
& $(-0.41)$ & $(-0.52)$ & $(0.59)$ & $(0.48)$ & $(0.59)$ \\
\hline Obs & 341 & 341 & 341 & 341 & 341 \\
\hline
\end{tabular}


A2. Analysis of Regression Results

Table 5.

Regression Results of VC and R\&D Expenditure

Use the following to interpret this table. (A) Coefficients significant at the $10 \%, 5 \%$ and $1 \%$ level are indicated with *, **, ***, respectively; the content in () is the $t$-statistic. (B) For variable definitions, please check Table 1. (C) Column (1) shows the regression results without control variables, columns (2)-(5) show the results that contain one more control variable than the previous column.

\begin{tabular}{|c|c|c|c|c|c|}
\hline \multirow{2}{*}{ Variables } & \multicolumn{5}{|c|}{ LnR\&D } \\
\hline & (1) & (2) & (3) & (4) & (5) \\
\hline \multirow[t]{2}{*}{ VC*Inv_after } & 0.032 & $0.085^{* *}$ & $0.075^{* *}$ & $0.074^{*}$ & $0.068^{*}$ \\
\hline & (1.53) & $(2.63)$ & $(2.27)$ & $(2.21)$ & (2.04) \\
\hline \multirow[t]{2}{*}{ Lnasset } & & $0.374^{* * *}$ & $0.409^{* * *}$ & $0.408^{* * *}$ & $0.398^{* * *}$ \\
\hline & & (21.88) & (23.13) & $(21.54)$ & (19.56) \\
\hline \multirow[t]{2}{*}{$R O E$} & & & $0.003^{* * *}$ & $0.003^{* * *}$ & $0.003^{* * *}$ \\
\hline & & & $(9.04)$ & $(8.94)$ & $(6.10)$ \\
\hline \multirow[t]{2}{*}{ Lngov } & & & & 0.002 & 0.003 \\
\hline & & & & $(0.53)$ & $(0.65)$ \\
\hline \multirow[t]{2}{*}{ Lev } & & & & & $0.001^{*}$ \\
\hline & & & & & (2.16) \\
\hline \multirow[t]{2}{*}{ Constant } & $15.706^{* * *}$ & $8.917^{* * *}$ & $8.121^{* * *}$ & $8.115^{* * *}$ & $8.218^{* * *}$ \\
\hline & $(195.50)$ & $(26.09)$ & (22.99) & $(23.61)$ & (23.38) \\
\hline Year & Controlled & Controlled & Controlled & Controlled & Controlled \\
\hline Industry & Controlled & Controlled & Controlled & Controlled & Controlled \\
\hline Obs & 1336 & 1336 & 1336 & 1336 & 1336 \\
\hline$R^{2}$ & 0.0658 & 0.3370 & 0.3618 & 0.3642 & 0.3454 \\
\hline
\end{tabular}

Table 5 shows that VC participation has a significant positive effect on company $R \& D$ expenditure, and the positive effect remains stable when considering other variables. This may be interpreted as showing that VC participation can promote $R \& D$ expenditure of the invested company. As for the control variables, the firm size variable (Lnasset) is positive at the $1 \%$ significance level, and the profitability variable (j) is positive at the $10 \%$ significance level. These results are reasonable, because companies with large scale and good profitability may more abundantly fund R\&D activities. Based on the analysis above, Hypothesis 1 is accepted, that is, VC firms can promote invested companies' innovation input. 


\section{B. Syndicated Investment and Innovation Input}

Table 6.

\section{Regression Results of Syndicated Investment and R\&D Expenditure}

Use the following to interpret this table. (A) Coefficients significant at the $10 \%, 5 \%$ and $1 \%$ level are indicated with *,**,***, respectively; the content in () is the $t$-statistic. (B) For variable definitions, please check Table 1. (C) Column (1) shows the regression results without control variables, columns (2)-(5) show the results that contain one more control variable than the previous column. (D) When analyzing the impact of syndicated investment characteristics on company's innovation input, separate testing of these factors may overestimate their effects on the dependent variable, so we have also tested all these factors in one model (column 4 in Panel B), and the results are consistent with the results of the separate tests. Due to space constraints, the regression results of the control variables are omitted from Panel B. Details can be obtained from authors.

\begin{tabular}{|c|c|c|c|c|c|}
\hline \multicolumn{6}{|c|}{ Panel A: syndicated investment and R\&D expenditure } \\
\hline \multirow{2}{*}{ Variables } & \multicolumn{5}{|c|}{ LnR\&D } \\
\hline & (1) & (2) & (3) & (4) & (5) \\
\hline \multirow[t]{2}{*}{ Syn } & $0.204^{* *}$ & 0.116 & $0.141^{*}$ & $0.145^{* *}$ & $0.125^{*}$ \\
\hline & $(2.27)$ & $(1.59)$ & $(1.95)$ & $(2.00)$ & $(1.75)$ \\
\hline \multirow[t]{2}{*}{ Lnasset } & & $0.876^{* * *}$ & $0.843^{* * *}$ & $0.832^{* * *}$ & $0.790^{* * *}$ \\
\hline & & $(12.54)$ & $(11.38)$ & $(11.12)$ & $(9.93)$ \\
\hline \multirow[t]{2}{*}{ ROE } & & & $0.015^{*}$ & $0.014^{*}$ & $0.014^{*}$ \\
\hline & & & $(1.92)$ & $(1.85)$ & $(1.81)$ \\
\hline \multirow[t]{2}{*}{ Lngov } & & & & 0.021 & 0.024 \\
\hline & & & & $(1.15)$ & $(1.31)$ \\
\hline \multirow[t]{2}{*}{ Lev } & & & & & 0.004 \\
\hline & & & & & $(1.18)$ \\
\hline \multirow[t]{2}{*}{ Constant } & $14.729^{* * *}$ & $-4.130^{* * *}$ & $-3.585^{* *}$ & $-3.69^{* *}$ & 0.004 \\
\hline & $(163.89)$ & $(-2.73)$ & $(-2.29)$ & $(-2.35)$ & $(1.18)$ \\
\hline Obs & 208 & 208 & 208 & 208 & 208 \\
\hline$R^{2}$ & 0.1837 & 0.5136 & 0.5257 & 0.5278 & 0.5317 \\
\hline \multicolumn{6}{|c|}{ Panel B: syndicated investment characteristics and R\&D expenditure } \\
\hline \multirow{2}{*}{ Variables } & \multicolumn{5}{|c|}{ LnR\&D } \\
\hline & $(1)$ & (2) & & & (4) \\
\hline \multirow[t]{2}{*}{ SynNum } & $0.104^{* *}$ & & & & $0.145^{* * *}$ \\
\hline & $(2.15)$ & & & & $(3.66)$ \\
\hline \multirow[t]{2}{*}{ SynRep } & & 0.035 & & & 0.002 \\
\hline & & $(0.35)$ & & & $(0.20)$ \\
\hline \multirow[t]{2}{*}{ ShareHetero } & & & & & $-0.327^{* * *}$ \\
\hline & & & & & $(-4.25)$ \\
\hline Obs & 145 & 145 & & & 145 \\
\hline$R^{2}$ & 0.5521 & 0.5264 & & & 0.6296 \\
\hline
\end{tabular}

Table 6 shows regression results of the relationship between syndicated investment and R\&D expenditure. First, syndicated investment has a significant positive correlation with invested company $R \& D$ expenditure, which indicates that companies supported by VC syndicated investment have higher innovation input than companies supported by only one VC firms. Second, the positive correlation between the number of syndicated investment members and company R\&D expenditure means that the greater the number of syndicated investment members, 
the higher the R\&D expenditure. Moreover, although the leading VC firms' age remains positive with the invested company's R\&D expenditure, the results are not significant. On the other hand, the coefficient of syndicated investment members' shareholding ratio heterogeneity is significantly negative, which means that the smaller the heterogeneity, the more positive the impact of syndicated investment on R\&D investment of the companies. In summary, Hypothesis 2, Hypothesis 3, and Hypothesis 5 are supported by our empirical evidence. ${ }^{11}$

\section{Robustness Test}

This part shows the results of robustness test, in which we created a dummy treatment group and a randomly selected experimental group.

\section{C1. Dummy Treatment Group}

To test the robustness of the conclusion that VC participation promotes enterprise innovation input, we set a dummy treatment group where VC participation happens one year later than the reality. The regression results are shown in Table 7. It is evident that VC participation has no significant positive impact on $\mathrm{R} \& \mathrm{D}$ expenditure, so the test result of Hypothesis 1 in the preceding section 3 is credible.

Table 7.

\section{Regression Results of VC and R\&D Expenditure (Dummy Treatment Group)}

Use the following to interpret this table. (A) Coefficients significant at the $10 \%, 5 \%$ and $1 \%$ level are indicated with $* * * * * *$, respectively; the content in () is the $t$-statistic. (B) For variable definitions, please check Table 1. (C) Column (1) shows the regression results without control variables, columns (2)-(5) show the results that contain one more control variable than the previous column.

\begin{tabular}{lccccc}
\hline \multirow{2}{*}{ Variables } & \multicolumn{5}{c}{ LnR\&D } \\
\cline { 2 - 6 } & $\mathbf{( 1 )}$ & $\mathbf{( 2 )}$ & $\mathbf{( 3 )}$ & $\mathbf{( 4 )}$ & $\mathbf{( 5 )}$ \\
\hline VC*Inv_after & 0.005 & 0.030 & 0.015 & 0.015 & 0.008 \\
& $(0.25)$ & $(1.06)$ & $(0.55)$ & $(0.53)$ & $(0.27)$ \\
Lnasset & & $0.354^{* * *}$ & $0.393^{* * *}$ & $0.391^{* * *}$ & $0.380^{* * *}$ \\
& & $(30.53)$ & $(29.51)$ & $(28.88)$ & $(26.67)$ \\
ROE & & $0.003^{* * *}$ & $0.003^{* * *}$ & $0.003^{* * *}$ \\
& & & $(10.67)$ & $(10.46)$ & $(6.96)$ \\
Lngov & & & 0.004 & 0.005 \\
& & & & $(0.98)$ & $(1.11)$ \\
Lev & & & & & 0.002 \\
& & & & & \\
Constant & 15.691 & $9.261^{* * *}$ & $8.369^{* * *}$ & $8.356^{* * *}$ & $8.468^{* * *}$ \\
& $(209.89)$ & $(39.36)$ & $(31.23)$ & $(31.63)$ & $(32.19)$ \\
\hline Year & Controlled & Controlled & Controlled & Controlled & Controlled \\
Industry & Controlled & Controlled & Controlled & Controlled & Controlled \\
\hline Obs & 1336 & 1336 & 1336 & 1336 & 1336 \\
$R^{2}$ & 0.0649 & 0.3294 & 0.3537 & 0.3574 & 0.3303 \\
\hline
\end{tabular}

${ }^{11}$ Due to length limitations, regression results of the control variables are omitted, but are available upon request. 


\section{C2. Randomly Selected Experimental Group}

To further test whether our results have omitted-variable bias, we conduct a placebo test. Specifically, in our sample, there are 227 VC-backed companies out of 341 companies. We first randomly select 227 companies from all 341 enterprises and mark them as VC-backed companies $(V C R=1)$, while the rest are designated non-VC-backed companies $(V C R=0)$. Then, we create a new variable, Fake $=V C R^{*} I n v \_a f t e r$. To avoid the impact of rare events, we repeat the random datagenerating process 500 times; the distribution of the 500 estimated coefficients is shown in Figure 1. It is evident that the figures are between 0 and 0.1 , and our true estimate (column 5 of Table 7) is the outlier in the placebo test. This indicates that our estimation results do not have serious bias due to omitted variables.

\section{Figure 1. Distribution of 500 Estimated Coefficients}

The $\mathrm{X}$-axis is the estimated coefficients of 500 random $V C R^{*}$ Inv_after, the curve is the density distribution of the estimated values, and the vertical line is our true estimate (column 5 of Table 7).

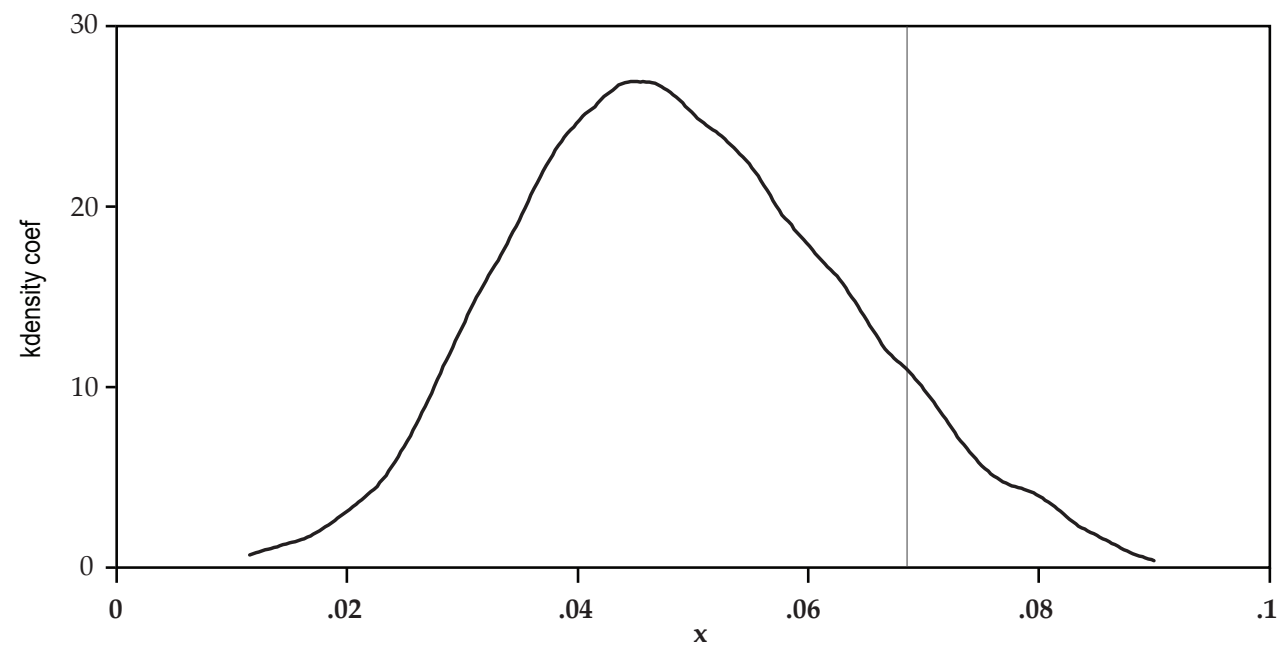

\section{CONCLUSION AND POLICY SUGGESTION}

This paper examines the relationship between VC and firm innovation input. The results show that VC participation significantly promotes the R\&D investment of the invested companies. This conclusion coincides with research conclusions found in the literature, such as Xu et al. (2015) and Gou and Dong (2014). While providing financial support, VC firms also guide the invested company to spend more on innovation input by participating in its business decision-making.

Further distinguishing companies that have obtained syndicated investment versus sole investment, we find that the number of syndicated investment members has a significant positive correlation with innovation input, while the heterogeneity of shareholding ratio among syndicated investment members is negatively correlated with innovation input. These conclusions relating to syndicated investment characteristics provide a valuable reference for enterprises 
that attach importance to innovation activities in searching for helpful fund providers, and they also provide a theoretical basis for VC firms to select their joint partners.

This paper's conclusions indicate that China should actively encourage and guide development of the VC industry, and constantly improve its policy, institutional, and supervision systems. The government could encourage VC firms to invest in startups through subsidies and tax incentives, among other measures, and encourage them to adopt a syndicated investment strategy, so that startups will be able to spend more on $R \& D$, and the innovation incubation system will become more efficient. In addition, the government could guide more social funds into the VC industry and reduce investment barriers, thereby broadening the financing channels for SMEs and providing adequate financial support for their innovation activities.

Acknowledgement: This research is supported by the Humanity and Social Science Youth Foundation of the Ministry of Education of China (19C11482075) \& Natural Science Foundation of Zhejiang Province (LY19G010005), China. This paper is a part of "Venture Capital Helps the Development of Hangzhou Hightech Enterprises"(20190834M26-1) which is a research project of Hangzhou's Scientific and Technological Commission, and is also a part of the field research project (18TYDC042) supported by the Graduate School in Zhejiang University of Finance \& Economics.

\section{REFERENCES}

Beckman, C. M., and Haunschild, P. R. (2002). Network Learning: The Effects of Heterogeneity of Partners' Experience on Corporate Acquisitions. Administrative Science Quarterly, 47, 92-124.

Holmstrom, B. (1989). Agency Cost and Innovation. Journal of Economic Behavior and Organization, 12, 305-327.

Chemmanur, T. J., and Loutskina, E. (2004). The Role of Venture Capital Backing in Initial Public Offerings: Certification, Screening, or Market Power?. Ssrn Electronic Journal.

Si, C., Wenlong, H., and Ran, Z. (2017). Venture Capital and Enterprise Innovation: Impact and Potential Mechanism . Management World, 2017, 158-169.

Keuschnigg, C. (2004). Venture Capital Backed Growth. Journal of Economic Growth, 9, 239-261.

Hongdong, F. (2010). Analysis and Solution of Financing Difficulties in Start-up Enterprises [D]. Beijing Jiaotong University.

Leiming, F., Dizhen, W., and Yahui, Z. (2012). Is VC a More Active Investor? - Evidence from Innovation Investment of Listed Companies on GEM. Financial Research, 10, 125-138.

Gompers, P. A. (1996). Grandstanding in the Venture Capital industry. Journal of Financial Economics, 42, 133-156.

Yannan, G., and Jing, D. (2014). Research on the Impact of Venture Capital on Enterprise Technology Innovation. Scientific Research Management, 2014, 35, 3542. 
Hellmann, T., and Puri, M. (2002). Venture Capital and the Professionalization of Start-Up Firms: Empirical Evidence. Journal of Finance, 57, 169-197.

Hsu, D. H. (2004). What Do Entrepreneurs Pay for Venture Capital Affiliation?. Journal of Finance, 59, 1805-1844.

Kaplan, S. N., Strömberg, P. (2004). Characteristics, Contracts, and Actions: Evidence from Venture Capitalist Analyses. Journal of Finance, 59, 2177-2210.

Kortum, S., and Lerner, J. (2000). Assessing the Contribution of Venture Capital to Innovation. Rand Journal of Economics, 31, 674-692.

Leland, H. E., and Pyle, D. H. (1977). Informational Asymmetries, Financial Structure, and Financial Intermediation. Journal of Finance, 32, 371-387.

Fan, L. (2015). Financing Constraints, Venture Capital and SME Growth - - Based on the Empirical Study of Chinese A-share Listed Companies. Journal of Hebei University of Economics and Business, 36, 72-79.

Yao, L., Yeqing, Z., Rui, J., et al. (2017). "Syndicate" Venture Capital and Enterprise Innovation. Financial Research, 159-175.

Popov, A., and Roosenboom, P. (2012). Venture capital and patented innovation: evidence from Europe. Economic Policy, 27, 447-482.

Weitao, S., and Liufen, H. (2014). Research on the Impact of Venture Capital Syndicated Investment on Corporate Governance of the Invested Companies - - Based on the Perspective of Board Structure and Executive Compensation Contract. Review of Finance and Economics, 64-71.

Tian, X. (2012). The Role of Venture Capital Syndication in Value Creation for Entrepreneurial Firms. Review of Finance, 16, 245-283.

Tian, X., and Wang, T. Y. (2011). Tolerance for failure and corporate innovation. The Review of Financial Studies, 27, 211-255.

Lanfang, W., and Yue, H. (2017). Does Venture Capital Promote Innovation Performance? An Empirical Test Based on Panel Data of Chinese Enterprises. Financial Research, 01, 177-190.

Chaopeng, W., Shinong, W., Jingya, C and Lu, W. (2012). Empirical Study on the Impact of Venture Capital on Investing and Financing Behavior of Listed Companies. Economic Research, 105-119.

Qiaozhen, W. (2009). Path Analysis of Independent Innovation in Venture Capital Supporting High-tech Industry . Management World, 07, 174-175.

Hao, X., Dizhen, W., and Jin, X. (2015). Venture Capital Background, Shareholding Ratio and R\&D Investment of Start-up Enterprises. Science Research, 33,15471554.

Zhenghua, Z., Yangyang, T., and Lei, W. (2015). The Impact of Joint Venture Capital on the Technological Innovation Capability of Target Enterprises- - Based on the Empirical Analysis of Listed Companies in Shenzhen GEM. Technological Economy, 34,24-30.

Zhijie, Z., and Tie, L. (2001). Venture Capital and Financial Innovation in the New Economy. Financial Research, 03,130-134.

Xueyong, Z., and Li, L. (2011). Venture Capital Background and Corporate IPO: Market Performance and Intrinsic Mechanism. Economic Research, 6, 118-132. 
This page is intentionally left blank 